\title{
Structural basis of PP2A activation by PTPA, an ATP- dependent activation chaperone
}

Feng Guo ${ }^{1}$, Vitali Stanevich ${ }^{1}$, Nathan Wlodarchak ${ }^{1}$, Rituparna Sengupta ${ }^{1}$, Li Jiang ${ }^{1}$, Kenneth A Satyshur $^{1}$, Yongna Xing ${ }^{1}$

${ }^{I}$ McArdle Laboratory, Department of Oncology, University of Wisconsin at Madison, School of Medicine and Public Health, Madison, WI 53706, USA

Proper activation of protein phosphatase 2A (PP2A) catalytic subunit is central for the complex PP2A regulation and is crucial for broad aspects of cellular function. The crystal structure of PP2A bound to PP2A phosphatase activator (PTPA) and ATP $\gamma$ S reveals that PTPA makes broad contacts with the structural elements surrounding the PP2A active site and the adenine moiety of ATP. PTPA-binding stabilizes the protein fold of apo-PP2A required for activation, and orients ATP phosphoryl groups to bind directly to the PP2A active site. This allows ATP to modulate the metal-binding preferences of the PP2A active site and utilize the PP2A active site for ATP hydrolysis. In vitro, ATP selectively and drastically enhances binding of endogenous catalytic metal ions, which requires ATP hydrolysis and is crucial for acquisition of pSer/Thr-specific phosphatase activity. Furthermore, both PP2A- and ATP-binding are required for PTPA function in cell proliferation and survival. Our results suggest novel mechanisms of PTPA in PP2A activation with structural economy and a unique ATP-binding pocket that could potentially serve as a specific therapeutic target.

Keywords: phosphatase; chaperone; activation; PP2A; cell proliferation and survival; catalytic metal ions Cell Research (2014) 24:190-203. doi:10.1038/cr.2013.138; published online 8 October 2013

\section{Introduction}

Protein phosphatase 2A (PP2A) is a major serine/threonine phosphatase that plays an essential role in many cellular processes $[1,2]$. The function of PP2A relies on proper activation of PP2A catalytic subunit (PP2Ac) and formation of diverse heterotrimeric holoenzymes. Activation of PP2Ac facilitates carboxyl-methylation of PP2Ac-tail, and stable association between PP2Ac and the scaffold (A) subunit [3-5], two critical steps toward holoenzyme assembly. The A-C heterodimer, also known as the common core enzyme, binds mutually exclusively with a variety of regulatory subunits for formation of diverse holoenzymes, which is highly regulated by methylation of PP2Ac-tail [6-10]. PP2A phosphatase activator (PTPA) is critical for many aspects of cellular function [11], likely due to the central role of PP2Ac activation in

Correspondence: Yongna Xing

E-mail: xing@oncology.wisc.edu

Received 5 June 2013; revised 4 August 2013; accepted 13 August 2013; published online 8 October 2013 complex PP2A regulation and formation of oligomeric complexes. Deregulation of PP2A function has been linked to multiple devastating human diseases, including cancer, neurodegenerative disorders, and heart failure $[1$, 2].

The active site of PP2Ac comprises protein loops connected to two central $\beta$-sheets. Six highly conserved residues on these loops, Asp57, His59, Asp85, Asn117, His 167, and His241, stably chelate two catalytic metal ions, which are common to all PPP family serine/threonine phosphatases (Supplementary information, Figure S1) [10]. Recent studies suggest that the PP2Ac active site conformation and its protein fold are quite dynamic $[3,12]$. Metal-free apo-PP2Ac has a propensity to partially unfold, which allows binding of $\alpha 4$ that plays a role in chaperoning partially folded PP2Ac for stable latency. $\alpha 4$ contacts both PP2Ac surface residues and inner structures that are exposed upon unfolding of a helix and a loop switch near the active site [12]. This induces a relay of conformational changes via the central $\beta$-sheets, which perturb the A-subunit binding site at the opposite surface [12]. These observations explain why activation 
of PP2Ac might be required for binding of the A-subunit and suggest that the conformation of apo-PP2Ac requires stabilization prior to its activation.

The yeast PTPA homologs are required for activation of PP2Ac in vivo [13]. This suggests that PTPA might play a role in stabilizing apo-PP2Ac for activation. The underlying mechanism of PP2A activation and PTPA function, however, remained largely elusive. In vitro, PTPA was found to stimulate the basal tyrosyl phosphatase (pTyr) activity of PP2A in the presence of $\mathrm{Mg}^{2+} / \mathrm{ATP}$, which requires ATP hydrolysis that occurs only in the presence of both PTPA and PP2A [14]. At a slight molar excess to PP2Ac, PTPA stimulates the pSer/Thr phosphatase activity of PP2Ac and promotes its methylation by LCMT-1 [3]. Furthermore, PTPA was proposed to have a prolyl isomerase activity [15]. Several structures of PTPA and its yeast homologs have been elucidated, which reveal that PTPA has a novel protein fold [1517]. The apo-PTPA structures, however, do not support ATP binding or the proposed prolyl isomerase activity of PTPA $[15,17]$. Understanding the function and mechanism of PTPA will rely on the structure of PTPA in complex with PP2A.

Here, we report the crystal structure of the PP2APTPA complex bound to ATP $\gamma \mathrm{S}$. Structural analysis and biochemical studies reveal how PTPA binding stabilizes the protein fold of apo-PP2Ac, orients ATP phosphoryl groups to bind directly to the PP2Ac active site, and together with ATP, selectively enhances coordination of proper catalytic metal ions for acquisition of $\mathrm{pSer} / \mathrm{Thr}$ specific phosphatase activity. Our results explain multiple intriguing biochemical properties of PTPA that are associated with PP2A activation, and suggest structurally economic mechanisms of PTPA as the activation chaperone of PP2Ac. Our study also reveals a unique ATPbinding pocket important for the function of PTPA in cell proliferation and survival that might serve as a specific therapeutic target.

\section{Results}

Crystallization and overall structure of the PP2A-PTPAATP $\mathrm{S}$ complex

The complex involving the full-length PP2A core enzyme (AC heterodimer) eluded crystallization. This is likely due to the instability of the PP2A-PTPA complex and the flexibility of the full-length A-subunit, an elongated protein comprising 15 HEAT (huntingtinelongation-A subunit-TOR) repeats $[10,18]$. To facilitate crystallization, PTPA was fused to mini-A constructs via a flexible linker to maintain 1:1 PTPA/PP2A stoichiometry. Mini-A contains HEAT repeats 1 and 11-15 to reduce flexibility while retaining protein folding and PP2Ac binding [19]. The mini-A construct was further modified, harboring internal deletions of residues 2-8 and 55-407 of the A-subunit and a F438Y mutation in HEAT repeat 11. These changes improved the internal packing of mini$\mathrm{A}$, and the folding and solubility of PTPA-mini-A fusion proteins. Among these, the F438Y mutation facilitates stacking interactions between residue 438 and Arg48 in mini-A. Diffracting crystals were obtained for a complex between PTPA ( $\Delta 1-18)$-mini-A fusion protein and PP2Ac ( $\triangle 294-309)$ bound to ATP $\gamma \mathrm{S}$ that blocks ATP hydrolysis. The structure was determined by molecular replacement and refined to $2.8 \AA$ (Table 1 and Figure $1 \mathrm{~A}$ ).

The structure reveals that PTPA and mini-A binds to the opposite surface of PP2Ac in a linear arrangement (Figure 1A). In crystal, PTPA binds to PP2Ac associated with mini-A from a different copy of the PTPA-mini-A

Table 1 Data collection and refinement statistics

\begin{tabular}{ll}
\hline & PP2A-PTPA-ATP $\gamma \mathrm{S}$ \\
\hline Data collection & P212121 \\
Space group & $50-2.82(2.87-2.82)$ \\
Resolution (outer shell) $(\AA)$ & 23656 \\
Unique observations & $7.5(4.5)$ \\
Data redundancy (outer shell) & $11.1(2.0)$ \\
I/sigma (outer shell) & $99.1 \%(90.4 \%)$ \\
Data coverage (outer shell) & $0.150(0.561)$ \\
$\mathrm{R}_{\text {sym }}$ (outer shell) & \\
Refinement & $50.0-2.8$ \\
Resolution $(\AA)$ & $22374(1209)$ \\
Number of reflections (free) & $98.9 \%$ \\
Data coverage & $19.1 \%$ \\
$\mathrm{R}_{\text {work }}$ & $24.2 \%$ \\
$\mathrm{R}_{\text {free }}$ & 6812 \\
Number of atoms (total) & 6585 \\
Protein & 52 \\
Ligand/ion & 175 \\
Waters & 0.006 \\
R.m.s.d. bond length $(\AA)$ & 1.165 \\
R.m.s.d. bond angles $\left({ }^{\circ}\right)$ & \\
Average B-factors & $24.0(37.2)$ \\
(plus TLS contribution) $\left(\AA^{2}\right)$ & \\
Ramachandran Plot & $96.4 \%$ \\
Preferred regions $(\%)$ & $3.2 \%$ \\
Allowed regions (\%) & $0.4 \%$ \\
Outliers (\%) & \\
\hline parentheses are for highest-resolution shell. & \\
\hline ray diffraction data were collected & one crystal. Values in \\
\hline
\end{tabular}



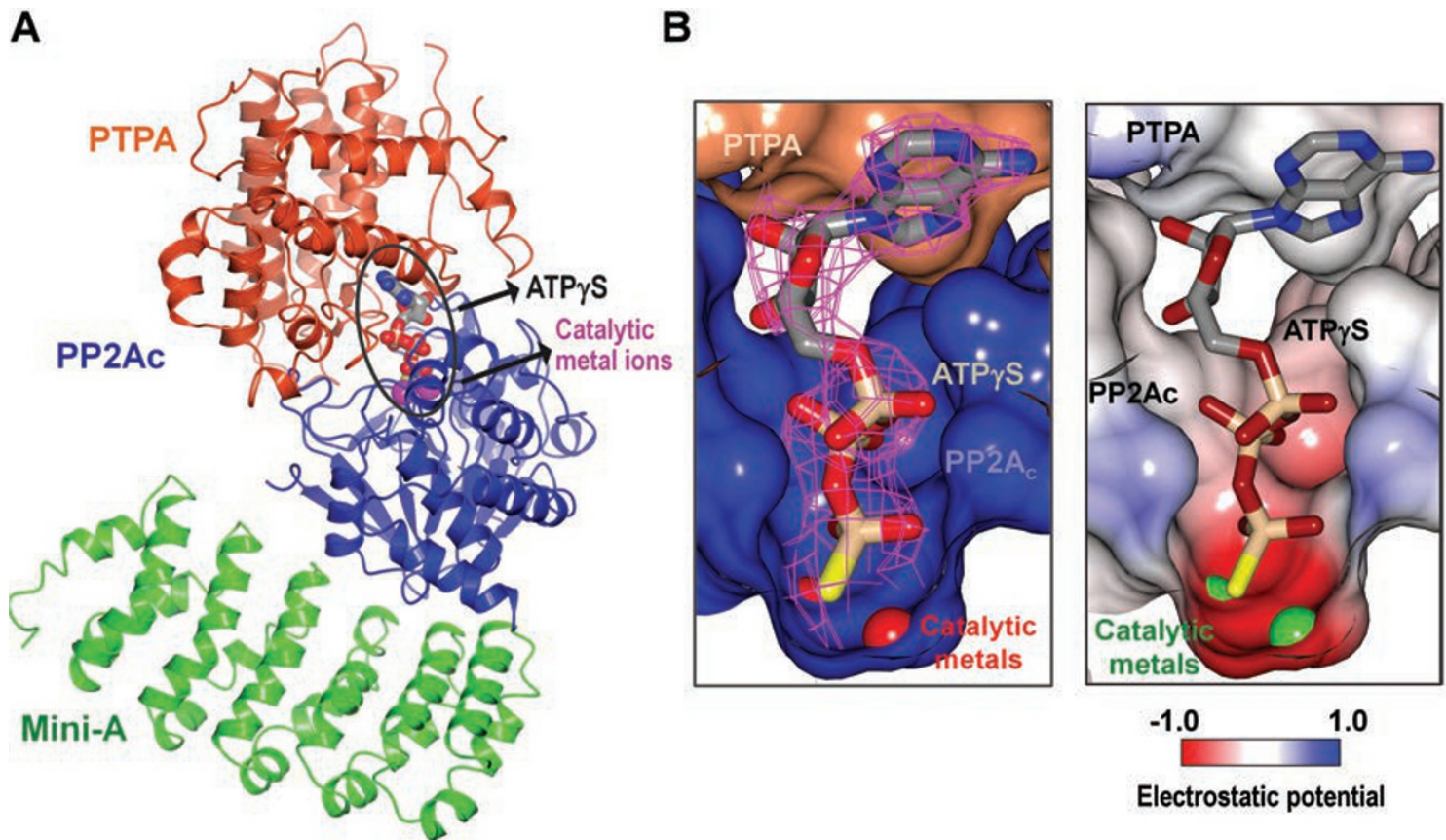

Figure 1 Structure of the PP2A-PTPA-ATP $\gamma$ S complex. (A) Overall structure of the PP2A-PTPA-ATP $\gamma$ S complex. Mini-A, PP2Ac and PTPA are shown in ribbon and colored green, blue and orange, respectively. (B) A slice of surface showing the combined ATP-binding pocket bound to ATP $\gamma \mathrm{S}$ (left) and its electrostatic potential (right). The $2 \mathrm{~F}_{\mathrm{o}}-\mathrm{F}_{\mathrm{c}}$ electron density for ATP $\gamma \mathrm{S}$ at $1.5 \sigma$ is shown in magenta. The color scheme is the same as in A. For all panels, ATP $\gamma \mathrm{S}$ is in cylinder and colored by atom type. PP2A catalytic metal ions are indicated by spheres.

fusion protein. This is because the length of the fusion linker connecting the C-terminus of PTPA and the N-terminus of mini-A is shorter than the distance between the two termini within the same complex. The PP2A-PTPA interface is thus involved in crystal packing, which is significantly larger than typical crystal packing interfaces and buries an otherwise solvent exposed surface area of $2800 \AA^{2}$. The importance of this interface in PP2APTPA interaction was supported by mutational analysis described later.

PTPA makes extensive contacts with structural elements surrounding the PP2Ac active site (Figure 1A, Supplementary information, Figure S2). Both PTPA and the PP2Ac active site interact with ATP $\gamma \mathrm{S}$ (Figure 1B). The negatively charged ATP phosphoryl groups directly contact the PP2Ac active site and are sandwiched by two patches of positively charged surfaces. The $\gamma$-phosphate of ATP directly interacts with catalytic metal ions. This architecture suggests that an ATP-binding pocket is created when the PP2A-PTPA complex forms, and that ATP hydrolysis is likely catalyzed by PP2Ac at this composite active site (Figure 2). The structure explains earlier observations that ATP hydrolysis requires both PP2A and PTPA [14], and that PTPA inhibits PP2A phosphatase activity when it is present at high molar excess [17]. Importantly, structural analysis and biochemical studies reveal a novel role and mechanism of PTPA in PP2A activation as a unique ATP-dependent chaperone.

\section{The structural basis of ATP binding and hydrolysis}

It is intriguing that ATP interacts with both PTPA and PP2A, and directly contacts the active site residues (Figure 2A). The adenine and ribose groups of ATP interact with PTPA similar to previously described [17]. These interactions orient the phosphoryl groups of ATP to directly coordinate the active site residues, making extensive hydrogen-bond (H-bond) and salt bridge interactions with the metal-chelating residue, Asn117, and two positively charged, substrate phosphate-binding residues, Arg89 and Arg214. ATP binding buries a surface area of $570 \AA^{2}$ and $500 \AA^{2}$ at the interface with PTPA and PP2Ac, respectively.

The $\gamma$ phosphate of ATP directly contacts catalytic metal ions, similar to the phosphoryl group of phosphoSer/Thr substrates, indicating that the PP2Ac active site might catalyze ATP hydrolysis (Figure 2B), similar to hydrolysis of phospho-Ser/Thr. The PP2A-PTPA complex exhibited a similar level of ATPase activity in the presence and absence of $1 \mathrm{mM}$ EDTA or $5 \mathrm{mM} \mathrm{Mg}^{2+}$ (Figure 2C), indicating that free metal ions are not re- 
A

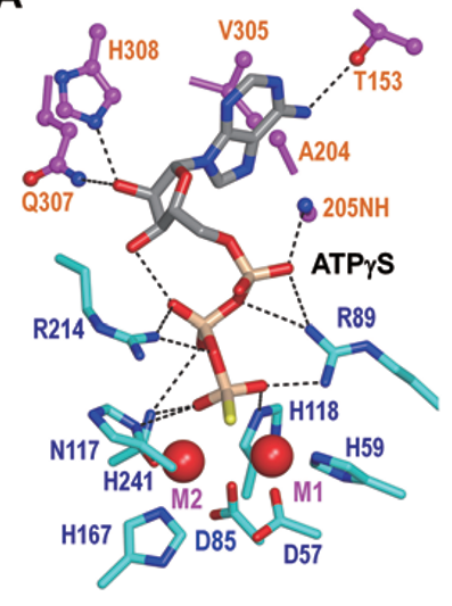

B

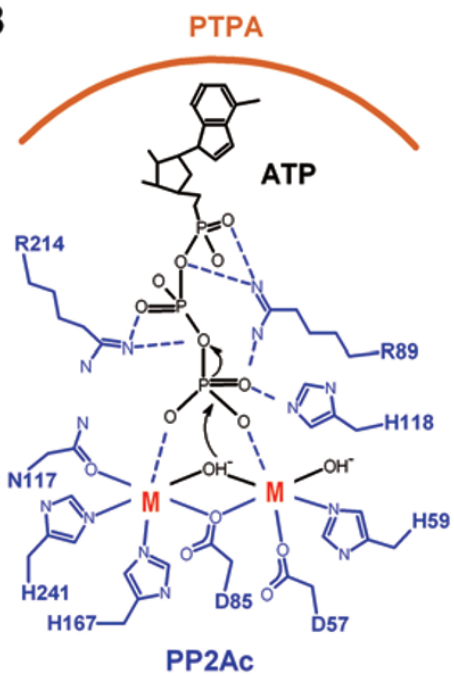

C

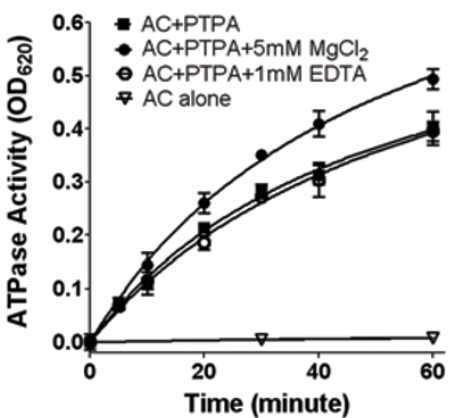

Figure 2 The combined ATP-binding pocket suggests a mechanism of ATP hydrolysis by PP2A at the composite active site. (A) A close-up view of the combined ATP-binding pocket of the PP2A-PTPA complex bound to ATP $\gamma$ S. Residues from PTPA and PP2Ac are in ball-and-stick and cylinder, and colored magenta and cyan, respectively. ATP $\gamma \mathrm{S}$ is shown in cylinder and colored by atom type. Catalytic metal ions are indicated by red spheres. The black dashed lines indicate $\mathrm{H}$-bonds. (B) Illustration of dual octahedral metal ion chelation at the PP2Ac active site by ATP $\gamma$ phosphate and six metal ion-chelating residues with proposed mechanism of ATP hydrolysis. (C) Time course of ATP hydrolysis by the complex of the PP2A core enzyme (AC heterodimer) and PTPA in the presence and absence of $5 \mathrm{mM} \mathrm{Mg}^{2+}$ or $1 \mathrm{mM}$ EDTA. AC alone was used as control.

quired for ATP hydrolysis, similar to dephosphorylation of PP2A substrates. ATP hydrolysis, however, follows much slower kinetics, with $K_{\text {cat }}$ about $1-2 /$ min, which is several hundred times smaller than that for dephosphorylation of pThr peptide. This might be in part because the ADP product of ATP hydrolysis is released by a much slower rate than Ser/Thr residues. Unlike Ser/Thr residues, ADP can interact with PTPA via its adenine group and with the arginine residues at the PP2Ac active site via its $\alpha / \beta$ phosphoryl groups, similar to ATP (Figure 2A). Collectively, these structural and biochemical observations suggest that the composite ATPase activity of the PP2A-PTPA complex most likely utilizes the PP2Ac active site for catalysis.

The PP2A-PTPA interface underlies the structural basis of PTPA as an activation chaperone

In the structure of the PP2A-PTPA-ATP $\gamma \mathrm{S}$ complex, three surface valleys of PTPA make extensive contacts with protruding structural elements surrounding the PP2Ac active site, including $\alpha 5$, the helix switch, the $\beta 2-\alpha 2, \beta 12-\beta 13$ and $\beta 10-\beta 11$ loops, and the peripheral $\beta$-sheet (Figures 3A, Supplementary information, Figure S2). Many of these structural elements are directly linked to the central $\beta$-sheets and the metal-chelating residues. The elongated $\beta 12-\beta 13$ loop of PP2Ac connects to both central $\beta$-sheets, and inserts into a deep pocket in PTPA formed by three helices and an extended loop, termed the "finger loop" (residues 199-218). The finger loop is reciprocally nestled into a PP2Ac active site groove formed by $\alpha 5$ and several active site loops connected to the first central $\beta$-sheet. In particular, $\operatorname{Arg} 268$ at the tip of the $\beta 12-\beta 13$ loop forms salt bridge and H-bond contacts with Asp213 and Asp214 in the finger loop at the bottom of a PTPA valley. Val209 and Trp210 at the tip of the finger loop interact with several residues in $\alpha 5$ and the $\beta 2-\alpha 2$ loop at the bottom of a PP2Ac active site groove. Next to the $\beta 12-\beta 13$ loop, the $\beta 10-\beta 11$ loop of PP2Ac connects to the 2 nd central $\beta$-sheet, and the metal-chelating residue His241; Leu243, and Met245 in this loop make hydrophobic contacts with Phe100 in PTPA. The PP2A residues at the interface with PTPA are highly conserved among PP2A, PP4, and PP6 (Supplementary information, Figure $\mathrm{S} 1$ ), suggesting that PTPA might regulate all PP2A-like phosphatases.

Previous studies indicate that the PP2Ac active site region is conformationally flexible and the protein fold spanning the active site and the central $\beta$-sheets are dynamic $[3,12]$. The mode of interaction between PP2A and PTPA suggests that PTPA might play an important role in stabilizing the conformation of the structural elements surrounding the PP2Ac active site, and the position of the metal-chelating residues and central $\beta$-sheets that are directly linked to these structural elements. This 
underlies a mechanism of PTPA to enhance LCMT-1 binding to the PP2Ac active site and to facilitate PP2A methylation [3]. The residues at the PP2Ac active site that interact with PTPA also interact with LCMT-1 (Supplementary information, Figure S1), suggesting that PTPA might stabilize the PP2Ac active site in a conformation suitable for both phosphatase activation and methylation by LCMT-1 [3], two critical steps toward the formation of holoenzymes.

PTPA stabilizes a proper protein fold of inactive PP $2 A c$ required for activation

Preparation of metal-free enzymes is required for investigating activation of many metalloenzymes [20]. Py- rophosphate (PPi) was shown to chelate and rapidly remove catalytic metal ions from PP2Ac, which, however, led to partial unfolding and aggregation of PP2Ac (Figure 3B) [12]. This indicates that apo-PP2Ac needs to be stabilized by protein chaperones prior to activation. Under otherwise identical conditions, aggregation of PP2Ac caused by PPi treatment was substantially blocked by coincubation with slight excess of PTPA (Figure 3B). Furthermore, analysis of secondary structure using circular dichroism (CD) spectrometry showed that the CD spectra of the PP2A-PTPA complex was not altered by PPi treatment (Supplementary information, Figure S3A). In contrast, the CD spectra of a PP2Ac- $\alpha 4$ mixture underwent significant changes after co-incubation with PPi (Supple-

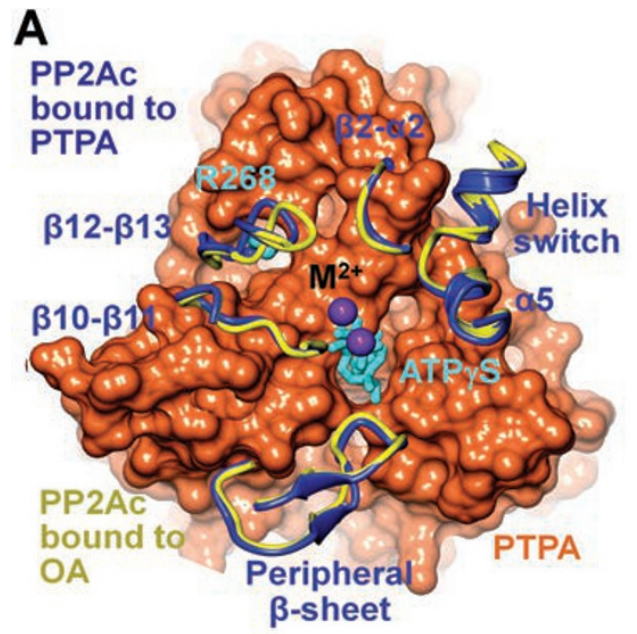

B

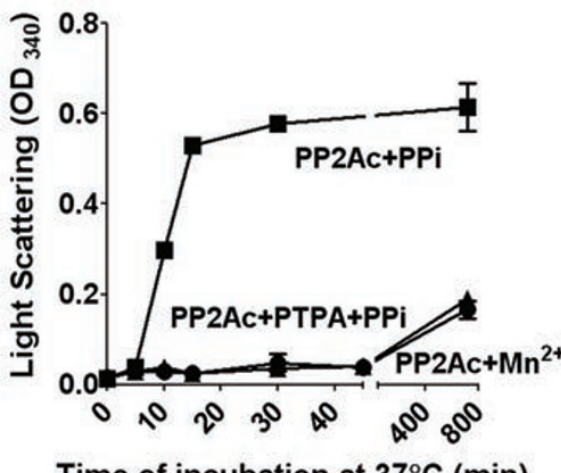

C
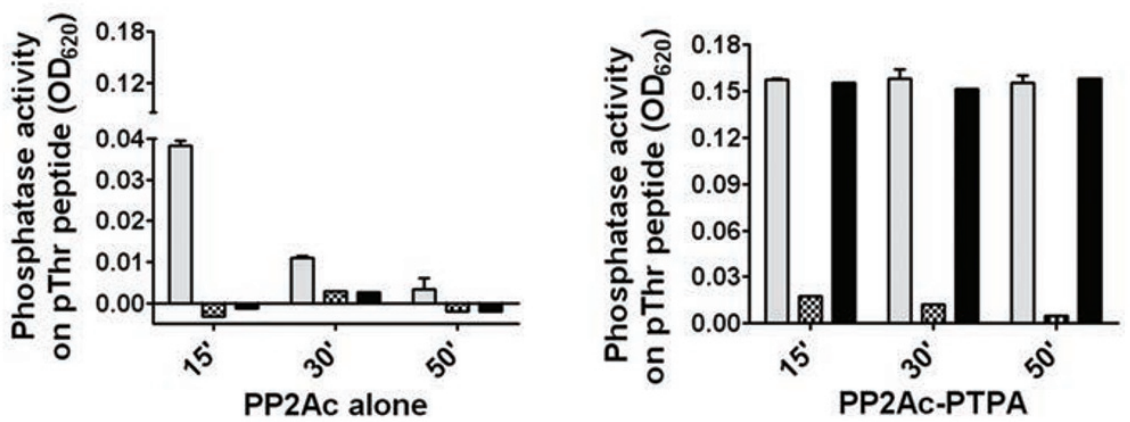

control $\mathrm{PPi}$

Reactivation by $\mathrm{Mn}^{2+}$

Figure 3 Restriction of the PP2Ac active site conformation by PTPA. (A) Contacts between the structural elements near the PP2Ac active site (ribbon, blue) and PTPA surface valleys (surface, orange). Arg268 of PP2Ac and ATP $\gamma$ S are in cylinder and colored cyan. Structural overlay with PP2Ac bound to okadaic acid (yellow, PDB code: 3IE4) shows a slightly opened active site conformation of the PTPA-bound PP2Ac. Catalytic metal ions are indicated by purple spheres. (B) Light scattering detected aggregation of PP2Ac upon PPi treatment (PP2Ac + PPi), which was suppressed by the presence of PTPA (PP2Ac + $\mathrm{PTPA}+\mathrm{PPi}$ ). (C) The phosphatase activity of PP2Ac after incubation at $37^{\circ} \mathrm{C}$ for the indicated duration with and without PPi and in the presence (right) and absence (left) of PTPA, followed by re-activation by $\mathrm{Mn}^{2+}$. For panels B-C, experiments were repeated three times; representative results are shown. 
mentary information, Figure S3B). The latter result is consistent with the recent observation that $\alpha 4$ stabilizes the metal-free PP2Ac in a soluble, partially folded form [12]. These results demonstrated an important function of PTPA in stabilizing the conformation and protein fold of apo-PP2Ac that might be required for activation.

We then investigated the role of PTPA as an activation chaperone. Free PP2Ac was intrinsically unstable and lost its phosphatase activity within an hour of incubation at $37^{\circ} \mathrm{C}$. In the presence of PTPA, full phosphatase activity was retained even after an extended incubation (Figure $3 \mathrm{C})$. Incubation of PP2Ac at $37{ }^{\circ} \mathrm{C}$ with PPi led to rapid and simultaneous loss of the phosphatase activity and the stably bound $\mathrm{Mn}^{2+}$ ions (PP2Ac was purified in the presence of $\left.\mathrm{Mn}^{2+}\right)$. The inactivated PP2Ac could not be re-activated by addition of $\mathrm{Mn}^{2+}$ (Figure 3C, Supplementary information, Figure S4). When PP2Ac was chaperoned by PTPA during PPi treatment, the inactivated PP2Ac could be fully re-activated by $\mathrm{Mn}^{2+}$ even after an extended incubation with PPi (Figure 3C, Supplementary information, Figure S4). $40 \%$ of $\mathrm{Mn}^{2+}$ remained bound to PP2Ac after 15 min co-incubation with PPi and PTPA (Supplementary information, Figure S4), despite a complete loss of phosphatase activity (Figure 3C). As loss of one metal ion is sufficient to abolish the phosphatase activity, this population of PTPA-chaperoned PP2Ac was most likely, singly-occupied by one metal ion. These results suggest that PTPA possesses an activation chaperone function and might preferentially stabilize the binding of one metal ion. This notion is consistent with the high expression level of PTPA in all mammalian cells in the micromolar range [21], similar to PP2Ac itself.

The mode of ATP binding suggests its role in chelation of catalytic metal ions

The direct contacts of the ATP phosphoryl groups with residues and catalytic metal ions at the PP2Ac active site pocket (Figure 2A-2B) led us to examine whether PTPA and ATP cooperatively facilitate chelation of two catalytic metal ions (Figure 4A). The metal-chelating residues at the M1 position, Asp57, His59, and Asp85, connect to $\beta 2$ and $\beta 3$, two $\beta$-strands at the center of the $1^{\text {st }}$ central $\beta$-sheet (Figure 4A). The structural elements linked to this $\beta$-sheet make predominant contacts with PTPA (Supplementary information, Figure S2), suggesting that PTPA might preferentially stabilize metal chelation at M1. At M2, Asp85, Asn117, His167, and His241 are constrained somewhat by PTPA and considerably by ATP phosphoryl groups (Figure 4A). His 167 packs against helix $\alpha 8$, which is linked to the peripheral $\beta$-sheet that contacts PTPA and ATP via Pro213 and Arg214, respectively. In addition, the ATP phosphoryl groups inter- act with Asn117, His118, and Arg89, restricting Asn117 and Asp85, respectively. These observations suggest that ATP might preferentially facilitate metal chelation at M2.

ATP might also alter metal chelation at the PP2Ac active site. The PP2Ac active site utilizes three oxygen $(\mathrm{O})$ and three nitrogen $(\mathrm{N})$ atoms for metal chelation, and the $\gamma$ phosphate of ATP provides two additional oxygen atoms in the PP2A-PTPA-ATP complex (Figure 2A-2B). A statistical study suggested that the atom type of metal ligand might affect metal ion preferences [22]. Based on this study, the PP2Ac active site would prefer binding of $\mathrm{Mn}^{2+}$ to $\mathrm{Mg}^{2+}$, as $\mathrm{Mn}^{2+}$ coordinates $\mathrm{O}$ and $\mathrm{N}$ at a comparable frequency and $\mathrm{Mg}^{2+}$ predominantly associates with oxygen atom [22]. This is consistent with the fact that $\mathrm{Mn}^{2+}$ exhibited a high activity and $\mathrm{Mg}^{2+}$ was barely active in phosphatase activation in vitro $[23,24]$. ATP might alter metal preferences of the PP2Ac active site by contributing two oxygen atoms, and increase the preference for $\mathrm{Mg}^{2+}$. This might provide a mechanism for acquiring authentic catalytic metal ions under physiological conditions.

\section{ATP enhances chelation of proper catalytic metal ions to} the PP2Ac active site

Several considerations of relevance to physiological conditions were made for exploring the role of ATP in PP2A activation. First, PP2Ac purified from erythrocytes was shown to contain stoichiometric $\mathrm{Zn}^{2+}$ and substoichiometric $\mathrm{Fe}^{2+}[25]$. Whether other metal ions could serve as authentic catalytic metal ions remained to be examined. Second, the cellular level of free transition metal ions is very low [26]. Although the total cellular $\mathrm{Zn}^{2+}$ is close to $\mathrm{mM}$, the free cellular $\mathrm{Zn}^{2+}$ was reported to be in the picomolar range, and the chelatable cellular $\mathrm{Fe}^{2+}$ in the micromolar range [27-29]. To study PP2A activation, the PTPA-chaperoned inactive PP2Ac were prepared in the absence of metal-chelating reagents and metal ions were titrated to below $1 \mu \mathrm{M}$ to correlate with physiological metal ion concentrations. Third, metal-free enzymes are normally prepared above $50-100 \mu \mathrm{M}$ to avoid activation by adventitious metal ions [20]. Even when chaperoned by PTPA, the inactive PP2Ac were prepared below $1 \mu \mathrm{M}$ to avoid aggregation. Stringent procedures [30-32] were thus followed to acquire "metal free" conditions (Materials and Methods).

Following these considerations, we first examined endogenous PP2A catalytic metal ions. We showed that PP2Ac purified from porcine brain contains stoichiometric $\mathrm{Zn}^{2+}$, diverse levels of $\mathrm{Fe}^{2+}$ and $\mathrm{Mg}^{2+}$, but no $\mathrm{Mn}^{2+}$ (Figure 4B), while the recombinant PP2Ac from insect cells has significant $\mathrm{Mn}^{2+}$ occupancy (data not shown). To investigate the effects of metal ions on phosphatase 


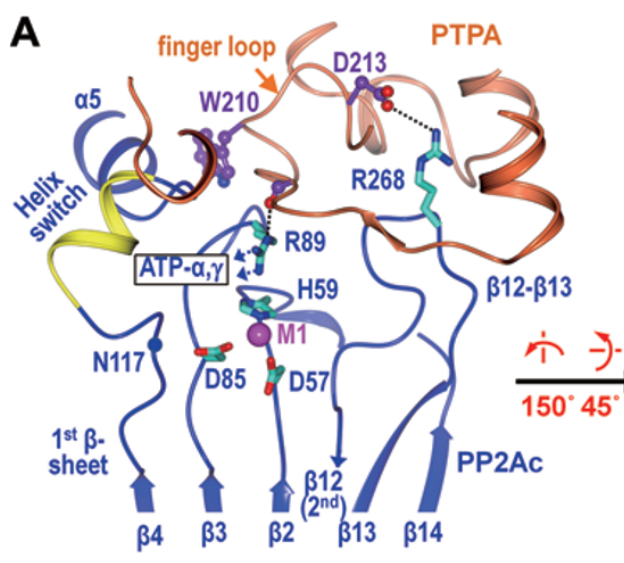

C

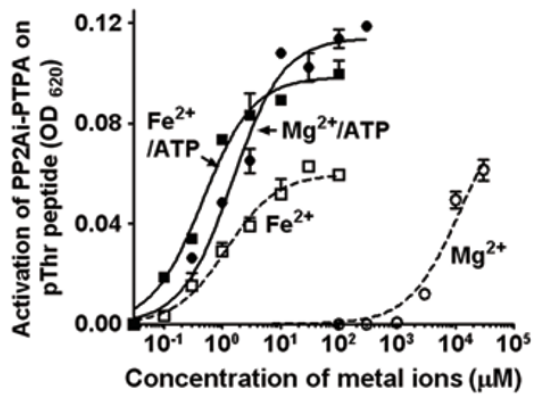

B
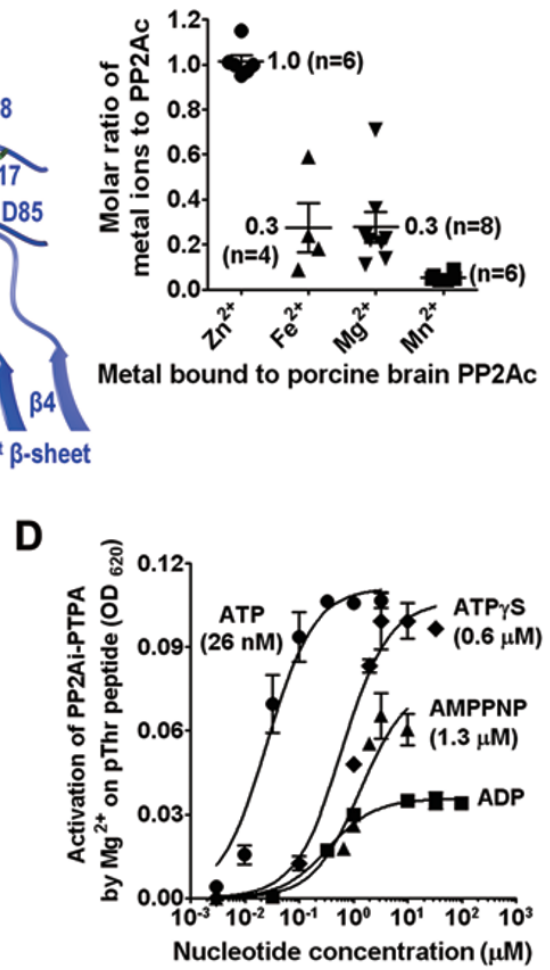

Figure 4 Metal chelation in the PP2A-PTPA-ATP $\gamma$ S complex and the role of ATP in selective enhancement of binding of proper catalytic metal ions. (A) Close-up views of metal-chelating residues at M1 and M2. The central $\beta$-sheets, peripheral $\beta$-sheet, active sites loops and contacts with PTPA and ATP are indicated. PP2Ac, its helix switch, and PTPA are shown in ribbon and colored blue, yellow, and orange, respectively. Residues from PTPA and PP2Ac are in ball-and-stick and cylinder, and colored purple and cyan, respectively. PP2A residues surrounding metal-chelating residues at M2 are colored green. ATP $\gamma S$ is shown in cylinder and colored by atom type. Catalytic metal ions are indicated by magenta spheres. The black dashed lines indicate H-bonds. (B) The level of metal ions associated with PP2Ac purified from porcine brains. (C) Activation of the pSer/Thr phosphatase by metal ions in the presence and absence of ATP. The calculated values for AC ${ }_{50}$ are summarized (right). (D) Activation of pSer/Thr phosphatase by $100 \mu \mathrm{M} \mathrm{Mg}^{2+}$ in the presence of increasing concentrations of ATP, ADP, ATP $\gamma$ S or AMPPNP. For panels C-D, experiments were performed in triplicate and repeated three times; representative results are shown.

specificity, the recombinant PP2Ac was exchanged for various metal ions, as desired (Supplementary information, Figure S5). PP2Ac enriched with $\mathrm{Zn}^{2+}$ and $\mathrm{Fe}^{2+}$, both retained detectable levels of $\mathrm{Mg}^{2+}$, exhibited highly specific phosphatase activity towards $\mathrm{pThr}\left(\mathrm{K}_{\mathrm{cat}}=360\right.$ $460 /$ min at $23{ }^{\circ} \mathrm{C}$ ), while PP2Ac with increased $\mathrm{Mn}^{2+}$ occupancy exhibited higher phosphatase activity towards pNPP (p-nitrophenyl phosphate) $\left(\mathrm{K}_{\mathrm{cat}} \sim 115 / \mathrm{min}\right.$ at $\left.37^{\circ} \mathrm{C}\right)$, a chemical mimic of pTyr (Supplementary information, Figure S5A).

Next, we prepared PTPA-chaperoned inactive PP2Ac, and investigated the effect of ATP on PP2A activation by $\mathrm{Mn}^{2+}$ and the endogenous metal ions identified above. As endogenous PP2Ac contains stoichiometric $\mathrm{Zn}^{2+}$ (Figure 4B) [25], the recombinant PP2Ac was first exchanged for $\mathrm{Zn}^{2+}$, and then incubated with PPi in the presence of PTPA. This gave PTPA-chaperoned inactive PP2Ac (PP2Ai-PTPA) that has partial $\mathrm{Zn}^{2+}$ occupancy but no $\mathrm{Mn}^{2+}$ (Supplementary information, Figure S6). After removal of free metal ions under "metal free" conditions, PP2Ai-PTPA was incubated with variable concentrations of $\mathrm{Mg}^{2+}, \mathrm{Fe}^{2+}, \mathrm{Zn}^{2+}$ or $\mathrm{Mn}^{2+}$ in the presence or absence of ATP. Metal chelation was monitored by acquisition of pSer/Thr phosphatase activity measured using a pThr peptide as substrate and the $\mathrm{AC}_{50}$ for each metal was determined (Figure $4 \mathrm{C}$ ). The $\mathrm{AC}_{50}$ of $\mathrm{Mg}^{2+}$ was around $12 \mathrm{mM}$ and $1.5 \mu \mathrm{M}$ in the absence and presence of ATP, respectively, indicating a decrease of four orders of magnitude. Activation by $\mathrm{Mg}^{2+} / \mathrm{ATP}$ was associated with increased $\mathrm{Mg}^{2+}$ occupancy (Supplementary information, Figure S6), consistent with the prediction above that ATP enhances the binding preferences for $\mathrm{Mg}^{2+}$ at the PP2Ac 
active site. ATP also lowered the $\mathrm{AC}_{50}$ of $\mathrm{Fe}^{2+}$ from around 1.2 to $0.4 \mu \mathrm{M}$. In contrast, the $\mathrm{AC}_{50}$ for $\mathrm{Mn}^{2+}$ was around $25 \mu \mathrm{M}$, and was minimally affected by ATP. The results show that $\mathrm{Mn}^{2+}$ has a lower activity than $\mathrm{Mg}^{2+}$ and $\mathrm{Fe}^{2+}$ to activate PP2Ai-PTPA under these in vitro conditions in the presence of ATP. Although $\mathrm{Zn}^{2+}$ could poorly activate PP2Ai-PTPA, $\mathrm{Mg}^{2+} /$ ATP-mediated activation was associated with an increase of $\mathrm{Zn}^{2+}$ occupancy, presumably acquired from scavenging $\mathrm{Zn}^{2+}$ ion (Supplementary information, Figure S6), suggesting that the PP2Ac active site might have a strong preference for $\mathrm{Zn}^{2+}$ as a partner for the second metal ion.

We then explored the role of ATP hydrolysis in PP2Ac activation. PP2Ai-PTPA was incubated with $\mathrm{Mg}^{2+}$ and ATP, ADP, ATP $\gamma \mathrm{S}$ or AMPPNP, prior to assessment of phosphatase activity (Figure 4D). Both nonhydrolysable ATP analogs, ATP $\gamma \mathrm{S}$ and AMPPNP, exhibited a drastically reduced activity in this PP2Ac activation process, suggesting that ATP hydrolysis is required for stable chelation of $\mathrm{Mg}^{2+}$ at the PP2Ac active site. The inability of ADP to enhance activation by $\mathrm{Mg}^{2+}$ suggests that a precise geometry of metal chelation by ATP is required for the role of ATP in PP2Ac activation.

Based on these data, we speculate that apo-PP2Ac might undergo activation in a multistep process, whereby $\mathrm{Zn}^{2+}$ might be chelated first in the presence of PTPA, presumably to the M1 position (Figure 4A and Supplementary information, Figure S2). The presence of ATP favors chelation of $\mathrm{Fe}^{2+}$ and $\mathrm{Mg}^{2+}$ in subsequent steps (Figure 4C). ATP hydrolysis is important for PP2A activation (Figure 4D), likely because this reaction leaves the acquired metal ions stably bound at the active site. In the absence of PTPA, ATP could effectively inactivate PP2A by eviction of catalytic metal ions, similar to PPi (data not shown). Other scenarios of metal chelation were also explored, but not discussed here due to a low relevance to endogenous PP2Ac.

PP2Ac activation by different metal ions is associated with different levels of persistent tyrosyl phosphatase activity

PTPA had been considered a phospho-tyrosyl phosphatase activator due to its ability to stimulate the tyrosyl phosphatase activity of PP2A in vitro [14]. To determine the relative contribution of this activity to PTPA function, we monitored the level of tyrosyl phosphatase activity of PP2A during PTPA-mediated activation. Activation of PP2Ai-PTPA by $\mathrm{Mg}^{2+} / \mathrm{ATP}, \mathrm{Mn}^{2+}$, or $\mathrm{Mn}^{2+} / \mathrm{ATP}$ was associated with increased activity toward pNPP, while $\mathrm{Mg}^{2+}$ alone could barely increase the phosphatase activity toward pNPP (Supplementary information, Figures S7A). This effect of ATP on metal ions in increased pTyr phosphatase activity correlates with activation of pSer/ Thr phosphatase activity (Figure 4C), suggesting that the previously observed stimulation of tyrosyl phosphatase activity of PP2A is likely a phenomenon associated with activation of $\mathrm{pSer} / \mathrm{Thr}$ phosphatase activity.

It is important to note that the identity of metal ions chelated at the active site influences substrate specificity (Supplementary information, Figure S5). Activation of PP2Ac with proper catalytic metal ions is thus important for controlling substrate specificity of PP2Ac. To test this notion, we showed that PP2Ac-PTPA activated by $\mathrm{Mg}^{2+}$, ATP displays variable levels of activity towards pNPP
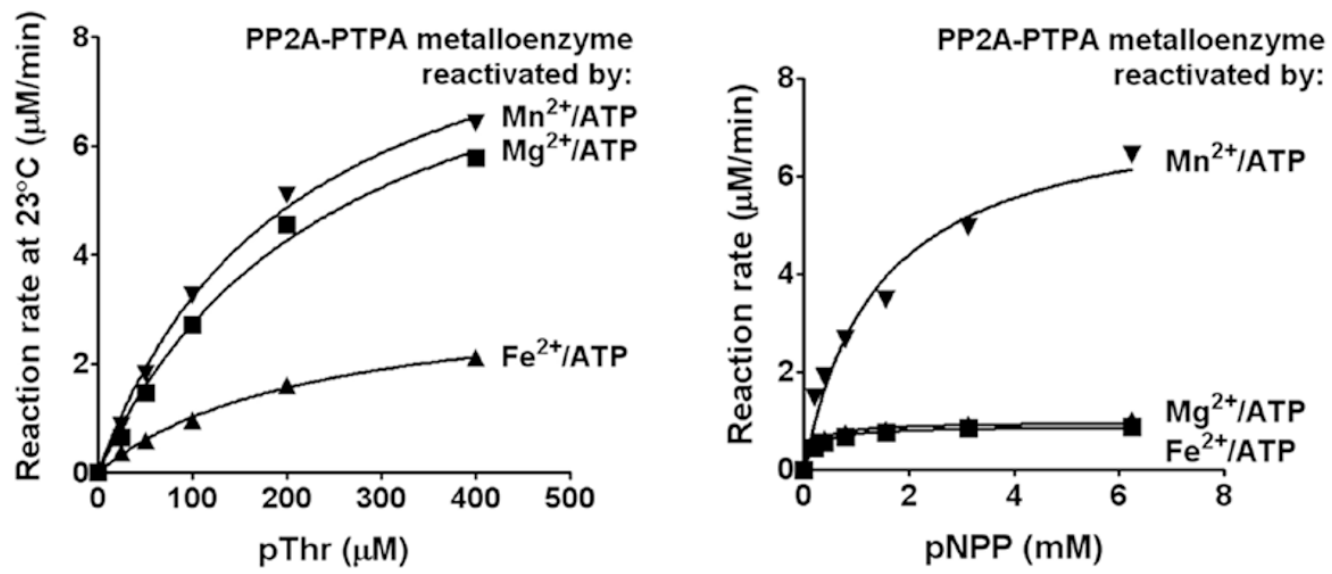

Figure 5 The substrate concentration-dependent rate of dephosphorylation of pThr and pNPP by PP2A-PTPA activated by different metal ions followed by removal of free metal ions. The activity toward pNPP remained high for the $\mathrm{Mn}^{2+}$-activated enzyme after removal of free metal ions, but not for the enzyme activated by $\mathrm{Mg}^{2+}$ and $\mathrm{Fe}^{2+}$. Experiments were performed in triplicate and repeated three times; representative results are shown in means \pm SEM. 


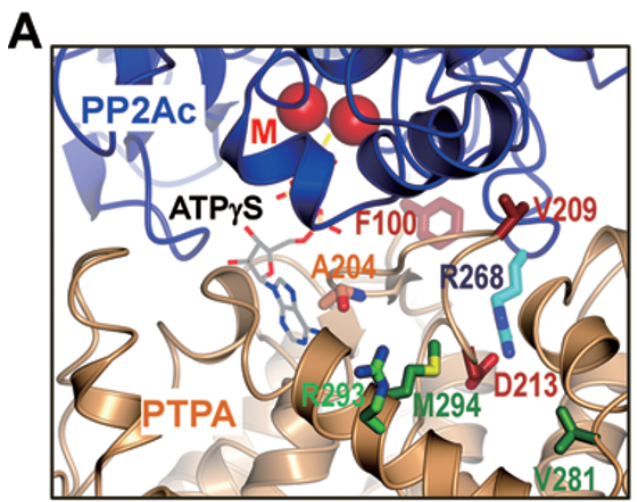

C

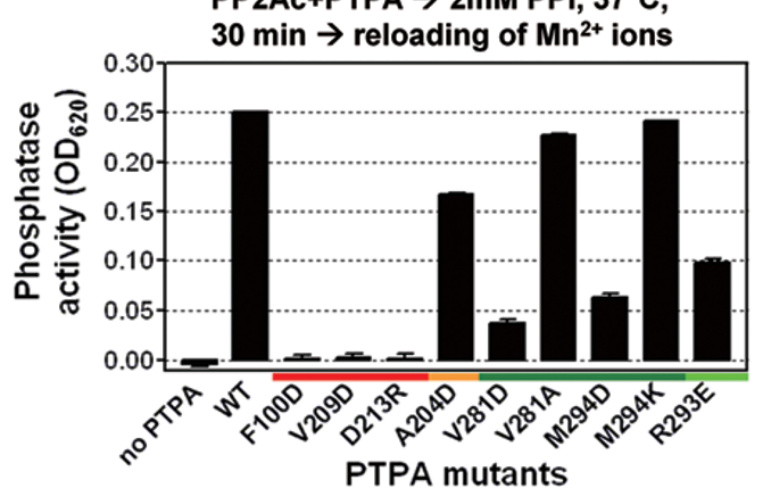

E

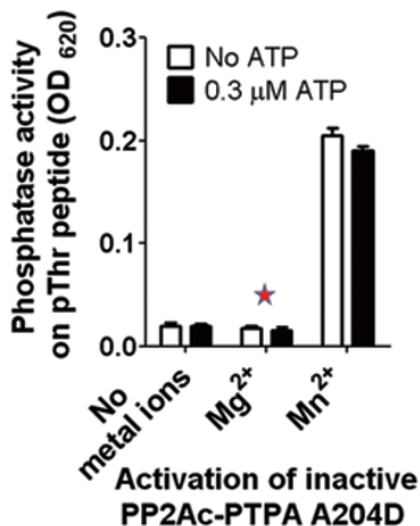

B
GST-AC pulldown wild type and mutant PTPA

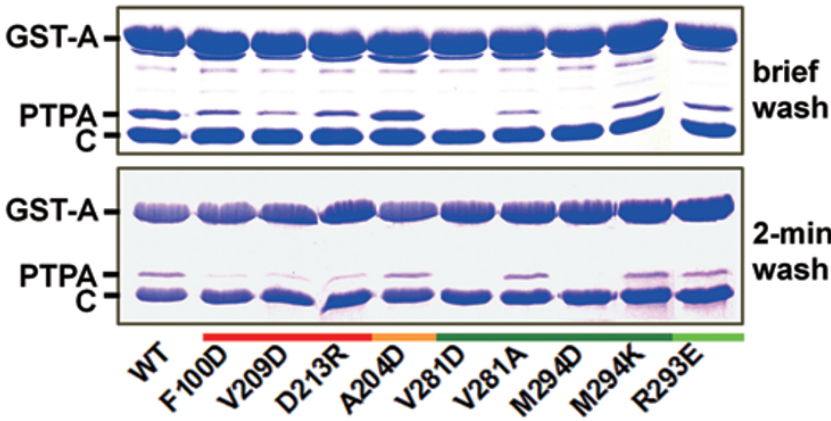

D

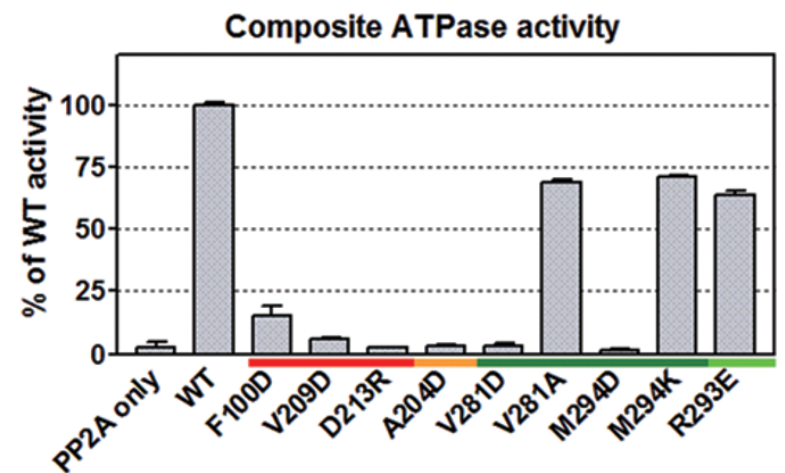

G
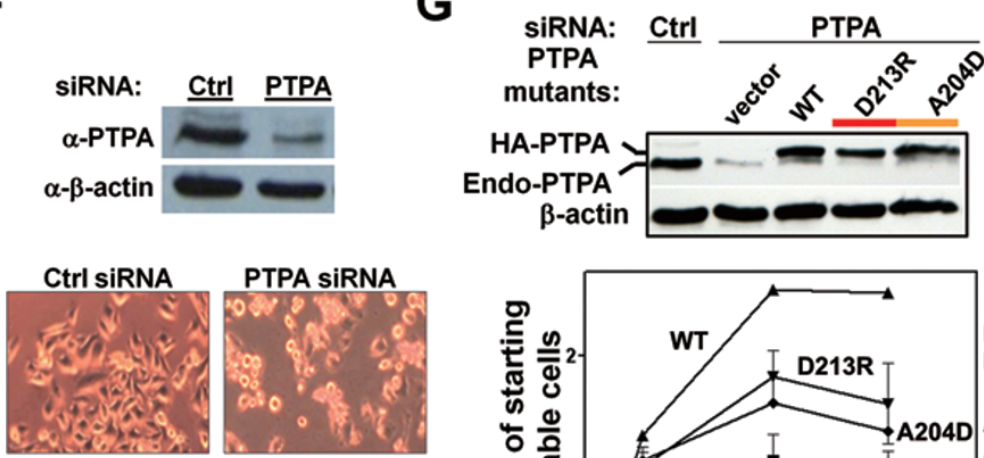


Figure 6 Site-directed mutagenesis of PTPA. (A) PTPA residues mutated shown on the structure of the PP2A-PTPA-ATP $\gamma$ S complex. Residues at the interface with PP2A and ATP are colored red and coral, respectively. Residues outside the interface whose mutations have no effect and those whose mutations distort protein conformations are colored green and dark green, respectively. The same color scheme for PTPA mutants is used in panel B-D and G. (B) Pull-down assay determined interactions between GST-tagged PP2A core enzyme (AC) and wild-type (WT) or mutant PTPA. (C) Stabilization of PP2Ac during PPi treatment by WT or mutant PTPA followed by reactivation by $\mathrm{Mn}^{2+}(100 \mu \mathrm{M})$. (D) The composite ATPase activity of PP2Ac and WT or mutant PTPA. (E) Activation of PP2Ai-PTPA bearing PTPA mutation, A204D, by $100 \mu \mathrm{M}$ metal ions in the presence and absence of ATP $(0.3 \mu \mathrm{M})$. (F) PTPA knockdown in HeLa cells by siRNA. Reduced PTPA level (top) and cell phenotype (bottom) are shown. (G) The ability of siRNA-resistant WT or mutant PTPA to complement cell growth defect in PTPA-knockdown cells (bottom). Top panel shows expression levels of recombinant and endogenous PTPA. For panels B-G, results represent three separate experiments. For panels $\mathbf{C}-\mathbf{E}$, assays were performed in triplicate. 
depending on the concentration of $\mathrm{Mg}^{2+}$ /ATP (Supplementary information, Figure S7B). After removal of $\mathrm{Mg}^{2+}$ /ATP, the metalloenzyme was barely active toward pNPP, but remained active toward pThr (Figure 5), suggesting that PP2Ac activated by $\mathrm{Mg}^{2+} / \mathrm{ATP}$ is highly specific for $\mathrm{pSer} / \mathrm{Thr}$. In contrast, the $\mathrm{Mn}^{2+}$-activated enzyme retained a high level of activity toward pNPP, even after removal of free metal ions (Figure 5 and Supplementary information, S7B). The ability of ATP to selectively enhance binding of proper catalytic metal ions, particularly cellular abundant $\mathrm{Mg}^{2+}$, might play a role in blocking $\mathrm{Mn}^{2+}$ binding and minimizing persistent nonspecific pTyr phosphatase activity.

Both PP2A- and ATP-binding are required for the function of PTPA in PP2A activation and its role in cell proliferation and survival

To corroborate our structural observations and further elucidate the role of ATP in PP2A activation and the cellular function of PTPA, we performed structure-based mutational analysis of PTPA residues in vitro. Several PTPA mutations at the interface with PP2Ac (Figure 6A), F100D, V209D, and D213R, reduced PP2A binding and the ability of PTPA to stabilize apo-PP2Ac for activation (Figure 6B-6C). In contrast, a mutation outside the interface, R293E, had much less effect on these activities (Figures 6A-6C). PTPA-A204D, a mutation at the interface with ATP, did not support ATP hydrolysis or activation of PP2Ac by $\mathrm{Mg}^{2+} / \mathrm{ATP}$ (Figure 6D-6E). Note that the previously identified putative PP2A-binding residues [17] are located near but not at the interface (Figure 6A). The effect of their mutations, V281D and M294D, on PTPA function (Figure 6B-6D) was likely caused by altered protein conformation. Different mutations to these sites, V281A and M294K, barely affected PTPA function (Figure 6B-6D). These data indicate that both PP2A- and ATP-binding are required for the function of PTPA in PP2Ac activation.

Similar to that previously shown, PTPA knockdown in mammalian cells caused cell death and attenuated cell proliferation (Figure 6F) [13]. PTPA-knockdown cells expressing siRNA-resistant PTPA-D213R or PTPAA204D grew more slowly than the knockdown cells expressing siRNA-resistant wild-type PTPA (Figure 6G). These data indicate that both PP2A- and ATP-binding are required for the cellular function of PTPA in cell proliferation and survival, most likely by affecting the process of PP2Ac activation.

\section{Discussion}

Our study here presents a structural model for un- derstanding the interaction between PTPA and PP2Ac, and the mechanism by which PTPA might ensure proper maturation of this essential phosphatase in eukaryotic cells. The results suggest that PTPA is an ATP-dependent activation chaperone. It stabilizes a conformation of apoPP2Ac that facilitates metal chelation and ATP binding and hydrolysis, whereby the precise geometry of ATP binding at the active site is important for selectively enhanced binding of proper catalytic metal ions, which influences phosphatase specificity (Figure 4). Our study provides important insights into the mechanism of activation chaperone, ATP function, metal chelation in biology, and phosphatase activation.

The dynamic protein fold of PP2Ac suggests that PP2Ac requires specialized chaperones to prevent misfolding and aggregation for proper folding and activation $[3,12]$. Our study provides five lines of structural and biochemical evidence that supports an activation chaperone function of PTPA: (1) its surface valleys make broad interdigital contacts with protruding structural elements surrounding the PP2Ac active site (Figure 3A and Supplementary information, Figure S2), underlying a structural basis for stabilizing the dynamic active site and protein fold of PP2Ac; (2) it hinders partial unfolding of apo-PP2Ac and prevents aggregation (Figure 3B); (3) it blocks changes of secondary structures of apoPP2Ac (Supplementary information, Figure S3A); (4) it increases the thermal stability of PP2Ac and prevents loss of phosphatase activity (Figure 3C); and (5) it stabilizes the inactive PP2Ac in a proper protein fold and conformation required for activation by metal ions and ATP (Figures 3C and 4C). The function of PTPA reflects the function of molecular chaperones in preventing protein misfolding and aggregation [33, 34], and resembles that of Hsp90, an activation chaperone that stabilizes the conformation of nuclear receptors required for ligand binding [35]. Collectively, these observations support the notion that PTPA is a specialized activation chaperone for PP2Ac.

The unique ATP-binding pocket in the PP2A-PTPA complex underlies important ATP functions and a mechanism of ATP hydrolysis that economically utilizes the PP2Ac active site (Figure 2). The latter explains the long puzzling observation that ATP hydrolysis can only occur in the presence of both PP2A and PTPA [14]. The mechanism of ATP in modulating metal chelation at the PP2Ac active site provides important general insights into chelation chemistry in cellular processes, an avid focus for metal research in biology. ATP drastically decreases the $\mathrm{AC}_{50}$ of cellular abundant $\mathrm{Mg}^{2+}$ in PP2A activation (Figure 4C), underlying an important role of $\mathrm{Mg}^{2+} /$ ATP in PP2Ac activation in mammalian cells, 
where free transition metal ions exist at a very low level [26], and might not be directly acquired by the PP2Ac active site. ATP binding is important for the function of PTPA in cell survival and proliferation (Figure 6G), suggesting that this unique ATP-binding pocket is potentially a valuable therapeutic target.

The mechanism of PTPA and ATP for acquiring proper catalytic metal ions and specific pSer/Thr phosphatase activity is crucial for proper PP2A activation and regulation. PTPA-mediated activation of PP2Ac by $\mathrm{Mg}^{2+} / \mathrm{ATP}$ is transiently associated with stimulation of tyrosyl phosphatase activity of PP2A previously observed in vitro [14] (Supplementary information, Figure S7B), which disappeared after removal of free $\mathrm{Mg}^{2+}$ ATP (Figure 5). In vivo, $\mathrm{PP} 2 \mathrm{~A}$ activation would facilitate methylation and holoenzyme assembly [3] that would in turn block PTPA binding and the associated tyrosyl phosphatase activity. The nonspecific pTyr phosphatase activity would persist when PP2Ac was activated by $\mathrm{Mn}^{2+}$ (Figure 5 and Supplementary information, Figure S7B), which might in part contribute to $\mathrm{Mn}^{2+}$ toxicity. Similar observations were made for protein phosphatase 1 (PP1), a closely related phosphatase [36]. Acquisition of pSer/Thr-specific activity of PP1 also relies on $\mathrm{Mg}^{2+} / \mathrm{ATP}$ with an unclear mechanism [36]. $\mathrm{Mn}^{2+}$ was often used in structural and biochemical studies of PP2A and PP1 in vitro, and was not expected to affect the structure of PP2A and PP1 complexes. Careful consideration of metal ions, however, is important for understanding certain aspects of phosphatase regulation, such as PP2A activation and the function of PTPA. In addition, PP2A-specific methylesterase (PME-1) was shown to inactivate PP2A via eviction of $\mathrm{Mn}^{2+}$ ions [19]. Further investigation of this phenomenon in context of endogenous catalytic metal ions might provide insights into the function of PME-1 in surveillance of the choice of PP2A catalytic metal ions.

Finally, consistent with our structural and biochemical observations, both PP2A- and ATP-binding are important for the function of PTPA in cell proliferation and survival (Figure 6). Defect in PTPA function and PP2A activation is expected to reduce PP2A methylation and holoenzyme assembly, and both are important for cell cycle progression and survival. The level of PP2A methylation was previously shown to vary during cell cycle [37]. LCMT-1 knockdown attenuated cell cycle progression and caused cell death [38, 39], so did loss of PP2A holoenzymes [40-42]. Whether PP2Ac can be activated by alternative mechanisms that lead to nonspecific pTyr phosphatase activity and cause cell death in the absence of PTPA remains to be determined. The dynamic nature of PP2Ac provides a molecular basis for co-regulation of PP2Ac activation, binding of the A-subunit, methylation, and assembly into holoenzymes [3, 12], which explains the common role of these processes in cell proliferation and survival.

\section{Materials and Methods}

\section{Protein preparation}

Human PTPA and missense mutants were cloned into pET21b (Invitrogen), and overexpressed at $23{ }^{\circ} \mathrm{C}$ in E. coli BL21 (DE3). The soluble fraction of $E$. coli cell lysate was purified over NiNTA (Qiagen), and further fractionated by anion exchange chromatography (Source 15Q, GE Healthcare). The $\alpha$ isoforms of the PP2A scaffold (A) and catalytic (C) subunits were used in this study. Human PP2A A $\alpha$ and PTPA-mini-A fusion proteins were cloned into pQlink vector, expressed and purified as GST-tagged proteins as described previously [10]. Expression and purification of human PP2A C $\alpha$ subunit and assembly of heterodimers of A $\alpha$ $\mathrm{C} \alpha$ and PTPA-mini-A fusion protein-C $\alpha$ followed the same procedures described previously [10].

\section{Crystallization and data collection}

Crystals of the PP2A-PTPA-ATP $\gamma$ S complex were grown at $18{ }^{\circ} \mathrm{C}$ using the sitting-drop vapor-diffusion method by mixing 6 $\mathrm{mg} / \mathrm{ml}$ heterodimer of a PTPA ( $\Delta 1-18)$-mini-A/C $\Delta 294-309$ (purified in the presence of $50 \mu \mathrm{M} \mathrm{MnCl}_{2}$ ) and $1 \mathrm{mM} \mathrm{ATP} \gamma \mathrm{S}$ with an equal volume of reservoir solution containing $0.1 \mathrm{M}$ MES at $\mathrm{pH}$ 6.5 and $10 \%-12 \%$ PEG 20000 in the presence and absence of 2 $\mathrm{mM} \mathrm{MgCl} 2$. The crystals appeared in two days and grew to full in a week. The crystals were flash frozen in liquid nitrogen after dehydration and being equilibrated in the reservoir buffer with $20 \%$ glycerol (v/v). Native datasets were collected at APS LS-CAT and processed using the software HKL2000 [43].

\section{Structure determination}

The structure of the PP2A-PTPA-ATP $\gamma \mathrm{S}$ complex was solved by molecular replacement using three models: PTPA (residues 22322, accession code: 2HV6), the PP2Ac (residues 6-293) from the structure of PP2A core enzyme (accession code: 2IE3), and miniA from the structure of the PP2A-PME-1 complex (accession code: $3 \mathrm{C} 5 \mathrm{~W}$ ). One complex was found per asymmetric unit. PP2A and PTPA loops at the interface with conformational changes were gradually built after the electron density map was improved; ATP $\gamma \mathrm{S}$ was added afterward. The structure was built using Coot [44] and refined using REFMAC restraints with TLS [45] and weights adjusted based on R-free. Three TLS groups were used: the $C$ subunit of PP2A (1-293), mini-A, and PTPA (22-322). The structure was refined to $2.8 \AA$, with the free and working R-factors

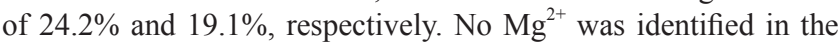
structure regardless of its presence in the crystallization buffer.

\section{GST-mediated pull-down assay}

The pull-down assay was performed following a previous procedure [17]. Briefly, wild-type or mutant PTPA (10 $\mu \mathrm{g}$ in $100 \mu \mathrm{l}$ or at the indicated concentrations) was mixed with $20 \mu 1$ glutathione resin with immobilized GST-tagged PP2A core enzyme (AC heterodimer, $10 \mu \mathrm{g})$ in the presence of $1 \mathrm{mg} / \mathrm{ml} \mathrm{BSA}$. The protein bound to resin was separated from unbound protein after incubation for the indicated time and analyzed by SDS-PAGE. All experiments were repeated three times. 


\section{Phosphatase assays}

PP2A phosphatase activity was measured using a synthetic pThr peptide (K-R-pT-I-R-R, Genemed Synthesis, Inc.). Briefly, pThr peptide ( $40 \mu \mathrm{M}$ or indicated concentrations) was added to PP2A sample $(50 \mathrm{nM})$ in the presence and absence of an equimolar PTPA in $50 \mu \mathrm{l}$ of assay buffer containing $10 \mathrm{mM}$ Tris $\mathrm{pH} 8.0,50$ $\mathrm{mM} \mathrm{NaCl}$, and $1 \mathrm{mM} \beta$-mecaptoethanol (BME). The reaction was performed at $30{ }^{\circ} \mathrm{C}$ for $15 \mathrm{~min}$ and stopped by addition of $100 \mu \mathrm{l}$ malachite green solution. The absorbance at $620 \mathrm{~nm}$ was measured after 10 min incubation at room temperature using plate reader (Spectra II, SLT). All experiments were performed in triplicate and repeated three times. Means \pm SEM were calculated.

For steady state enzyme kinetics, $50 \mu 1$ titrated phosphate solutions were measured in parallel as standards to determine the concentration of phosphate released in assays. The rate of phosphate release versus the concentration of $\mathrm{pThr}$ peptide was fitted in GraphPad Prism (GraphPad Software, Inc.) for calculation of $\mathrm{K}_{\mathrm{m}}$ and $\mathrm{K}_{\text {cat }}$.

\section{Phosphatase activity toward pNPP}

The tyrosyl phosphatase activity of PP2A was measured using p-nitrophenyl phosphate (pNPP, 99.88\%, AMRESCO, Inc.) as substrate. The experiment was performed on a 96-well plate. Briefly, $50 \mu \mathrm{l} \mathrm{pNPP}$ (50 mM or indicated concentrations) in $50 \mathrm{mM}$ Tris$\mathrm{HCl} \mathrm{pH} 8.2,1 \mathrm{mM}$ DTT, and $0.1 \mathrm{mg} / \mathrm{ml}$ BSA was added to each well. The reaction was initiated by addition of $50 \mu \mathrm{l}$ of the PP2AcPTPA complex $(0.6 \mu \mathrm{M}$ or indicated concentrations $)$. The plate was incubated at $37{ }^{\circ} \mathrm{C}$ for $5-20 \mathrm{~min}$, and the enzymatic reaction product was measured by absorbance at $405 \mathrm{~nm}$ using plate reader (Spectra II, SLT). The experiment was performed in triplicate and repeated three times. Means $\pm \mathrm{SEM}$ were calculated.

For steady state enzyme kinetics, pNPP fully hydrolyzed by PP2A was used as standards to calculate the concentration of the enzymatic product of pNPP. The reaction rate versus pNPP concentration was fitted in GraphPad Prism (GraphPad Software, Inc.) for calculation of $\mathrm{K}_{\mathrm{m}}$ and $\mathrm{K}_{\text {cat }}$.

\section{ATPase activity}

The activated PP2Ac-PTPA complex $(0.3 \mu \mathrm{M})$ was purified away from free metal ions and mixed with $0.2 \mathrm{mM}$ ATP in $50 \mu \mathrm{l}$

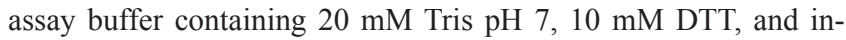
cubated at $37{ }^{\circ} \mathrm{C}$ for the indicated duration in the presence and absence of $5 \mathrm{mM} \mathrm{MgCl}$ or $1 \mathrm{mM}$ EDTA. The free phosphate was detected at the indicated time by malachite green as described above. All experiments were performed in triplicate and repeated three times. Means $\pm \mathrm{SEM}$ were calculated.

\section{Light scattering}

To determine the ability of PTPA to stabilize the protein fold of PP2Ac during PPi treatment, $0.5 \mathrm{mg} / \mathrm{ml}$ of PP2Ac was mixed with $2 \mathrm{mM}$ PPi in the presence and absence of $0.8 \mathrm{mg} / \mathrm{ml}$ of PTPA in $200 \mu \mathrm{l}$ assay buffer and incubated at $37^{\circ} \mathrm{C}$. The absorbance at 340 $\mathrm{nm}$ was measured at the indicated time. Incubation of PP2Ac with $50 \mu \mathrm{M}$ of $\mathrm{MnCl}_{2}$ was used as control. The experiments were performed in triplicate and repeated three times. Means \pm SEM were calculated.

\section{Circular dichroism (CD) spectrometry}

To measure changes of secondary structure of the PP2A-PTPA complex after inactivation by PPi, $0.12 \mathrm{mg} / \mathrm{ml}$ of PP2A-PTPA complex was prepared in buffer containing $10 \mathrm{mM} \mathrm{KH}_{2} \mathrm{PO}_{4}, \mathrm{pH} 7.5$, and $50 \mathrm{mM} \mathrm{Na}_{2} \mathrm{SO}_{4}$ using gel filtration chromatography. The $\mathrm{CD}$ spectra were acquired after incubation in the presence of $100 \mu \mathrm{M}$ $\mathrm{MnCl}_{2}$ or $2 \mathrm{mM} \mathrm{PPi}$ at $37{ }^{\circ} \mathrm{C}$ for 30 min using Model 202SF Circular Dichroism Spectrophotometer (Aviv Biomedical).

\section{Inactivation and re-activation of PP2Ac bound with $\mathrm{Mn}^{2+}$}

PP2Ac $\left(3 \mu \mathrm{M}\right.$, purified in the presence of $\left.50 \mu \mathrm{M} \mathrm{MnCl}_{2}\right)$ alone or mixed with PTPA $(5 \mu \mathrm{M})$ was co-incubated with $1 \mathrm{mM}$ PPi at $37{ }^{\circ} \mathrm{C}$ for the indicated time. Samples were then diluted $100-$ fold into buffer containing $50 \mathrm{mM}$ MOPS at $\mathrm{pH} 7.2,10 \mathrm{mM}$ DTT, with and without $\mathrm{Mn}^{2+}$ for re-activation at $37^{\circ} \mathrm{C}$ for $5 \mathrm{~min}$. Phosphatase activity was measured as described above. The level of $\mathrm{Mn}^{2+}$ associated with PP2A samples before and after re-activation was determined by ICP-MS (Center for Applied Isotope Studies, University of Georgia) after unbound metal ions were removed by gel filtration chromatography using weakly buffered "metal free" water containing $0.5 \mathrm{mM}$ Tris $\mathrm{pH}$ 7.5. All experiments were performed in triplicate and repeated three times. Means \pm SEM were calculated.

\section{"Metal free" conditions}

To minimize the contamination of trace amount of divalent metal ions, all "metal free" buffers and reagents were prepared using deionized water (Barnstead System) and further purified by and stored with Chelex ${ }^{\circledR} 100$ (Sigma) before use. The plastic containers and tips used for PP2Ai-PTPA, ICP-MS samples, and activation of PP2Ai-PTPA were pre-treated with $10 \mathrm{mM} \mathrm{HCl}$ overnight followed by rinsing with deionized water. Gel filtration columns (Superdex 200, GE Healthcare) used for "metal free" procedures were washed by 2 column volumes of $20 \mathrm{mM}$ EDTA and soaked overnight before equilibrium with "metal free" buffers.

\section{Metal exchange and determination of metal effect on phos- phatase activity}

The recombinant PP2Ac purified in the absence of divalent metal ions was incubated with $300 \mu \mathrm{M} \mathrm{Zn}{ }^{2+}, \mathrm{Fe}^{2+}, \mathrm{Zn}^{2+} / \mathrm{Fe}^{2+}$, and $\mathrm{Zn}^{2+} / \mathrm{Mn}^{2+}$ at $4{ }^{\circ} \mathrm{C}$ overnight to displace the original metal ions at the active site. The phosphatase activity toward $\mathrm{pThr}$ peptide and pNPP was determined after removal of free metal ions by first gel filtration chromatography using "metal free" buffer containing 10 $\mathrm{mM}$ Tris $\mathrm{pH}$ 8.0, $50 \mathrm{mM} \mathrm{NaCl}, 1 \mathrm{mM}$ BME. The metal contents were determined by ICP-MS after $2^{\text {nd }}$ gel filtration chromatography using weakly buffered "metal free" water containing $0.5 \mathrm{mM}$ Tris $\mathrm{pH} 7.5$.

\section{Generation and activation of PP2Ai-PTPA}

The PP2Ac after overnight metal exchange with $300 \mu \mathrm{M} \mathrm{Zn}{ }^{2+}$ at $4{ }^{\circ} \mathrm{C}$ was inactivated by $3 \mathrm{mM}$ PPi in the presence of 1.5 molar amount of PTPA at $37^{\circ} \mathrm{C}$ for $30 \mathrm{~min}$. Free metal ions and PPi were removed by gel filtration chromatography using "metal free" buffer containing $10 \mathrm{mM}$ Tris $\mathrm{pH}$ 8.0, $50 \mathrm{mM} \mathrm{NaCl}$, and $1 \mathrm{mM}$ BME.

The inactivated complex (PP2Ai-PTPA) was incubated with $\mathrm{Fe}^{2+}, \mathrm{Mg}^{2+}, \mathrm{Mn}^{2+}$, and $\mathrm{Zn}^{2+}$ in the presence and absence of ATP at the indicated concentrations at room temperature for $10 \mathrm{~min}$ (albeit activation was instantaneous). Incubation with $\mathrm{Fe}^{2+}$ was performed in the presence of $20 \mathrm{mM}$ ascorbic acid to prevent iron oxidation [25]. The phosphatase activity following activation was deter- 
mined using pThr peptide and pNPP as substrates. The phosphatase activity was also determined after removal of free metal ions and ATP by the $1^{\text {st }}$ gel filtration chromatography described above.

The metal contents of PP2Ai-PTPA and the metalloenzymes activated by $\mathrm{Mg}^{2+} /$ ATP were determined by ICP-MS after $2^{\text {nd }}$ gel filtration chromatography to replace buffer with weakly buffered "metal free" water containing $0.5 \mathrm{mM}$ Tris $\mathrm{pH}$ 7.5. To ensure complete removal of unbound $\mathrm{Mg}^{2+} / \mathrm{ATP}$ from PP2Ac, excess okadaic acid was added to the activated enzyme to block the binding of ATP/PTPA before samples were applied to gel filtration chromatography $\left(1^{\text {st }}\right.$ and $\left.2^{\text {nd }}\right)$ and ICP-MS analysis. All experiments were performed in triplicate and repeated three to five times. Mean \pm SEM were calculated.

\section{Mammalian cell culture, western blot, and cell proliferation assay}

PTPA knockdown was performed by transfection of PTPA siRNA (Ambion, s10978) to HeLa cells around 30\% confluency. HA-tagged human PTPA or mutants resistant to PTPA siRNA were cloned into a murine leukemia retroviral vector with a PGK1 promoter for expression at a physiological level. The retrovirusinfected cells were transfected with siRNAs and collected after $72 \mathrm{~h}$. Cell extracts were examined by western blot using antibodies that specifically recognize human PTPA (Cell Signaling, 3330S), and actin control (Millipore, MAB1501).

Cell proliferation was determined using a viable cell assay. Briefly, $24 \mathrm{~h}$ after transfection of PTPA siRNA, about $1000 \mathrm{HeLa}$ cells that express WT or mutant PTPA were placed into each well of 96-well plates, and cultured in DMEM containing 10\% FBS. The growth of viable cells was determined using CellTiter-Glo luminescent cell viability assay (Promega) at the indicated time. The experiments were performed in triplicate and repeated three times.

\section{Determination of endogenous catalytic metal ions}

Endogenous PP2Ac was purified from porcine brains following a procedure modified from the studies of Tran et al. [46]. Briefly, the tissue was homogenized by dounce tissue grinder in $10 \mathrm{mM}$ Tris buffer $\mathrm{pH} 8.0$ containing $50 \mathrm{mM} \mathrm{NaCl}, 1 \mathrm{mM}$ BME, $100 \mu \mathrm{M}$ EDTA. Following centrifugation, PP2A was precipitated by ammonium sulfate with $70 \%$ saturation from supernatant, followed by precipitation by $95 \%$ ethanol. The free PP2Ac in precipitate was further purified over GS4B resin with immobilized GST-A $\alpha$ to assemble PP2A core enzyme, and the flowthrough depleted of PP2Ac passed over the second GS4B resin with immobilized GST$\mathrm{A} \alpha$ as a control. Both core enzyme and $\mathrm{A} \alpha$ control were further purified as previously described in the presence of $10 \mu \mathrm{M}$ EDTA [10], resulting in a minimum of $95 \%$ homogeneity for both samples. All samples were purified by gel filtration chromatography and analyzed by ICP-MS as described above. The protein amounts were normalized on SDS-PAGE after Coomassie blue staining. Metal contents of PP2Ac were determined by subtraction of metal contents with corresponding A $\alpha$ control from those of the PP2A core enzyme. The metal contents of recombinant PP2Ac expressed in insect cells were determined in a similar way.

\section{Acknowledgments}

We thank David Smith (APS LS-CAT) for assistance on X-ray diffraction data collection, Drs Egon Ogris (Medical University of
Vienna) and David Brautigan (University of Virginia) for discussion. This work was supported by ACS research scholar grant (Y Xing), R01 GM096060-01 (Y Xing), T32 CA009135 (N Wlodarchak), and Morgridge Institute for Research predoctoral fellowship (R Sengupta). The atomic coordinate of the PP2A-PTPA-ATP $\gamma \mathrm{S}$ complex was deposited in the Protein Data Bank with accession code 4LAC.

\section{References}

1 Janssens V, Goris J. Protein phosphatase 2A: a highly regulated family of serine/threonine phosphatases implicated in cell growth and signalling. Biochem J 2001; 353(Pt 3):417-439.

2 Virshup DM. Protein phosphatase 2A: a panoply of enzymes. Curr Opin Cell Biol 2000; 12:180-185.

3 Stanevich V, Jiang L, Satyshur KA, et al. The structural basis for tight control of PP2A methylation and function by LCMT1. Mol Cell 2011; 41:331-342.

4 Hombauer H, Weismann D, Mudrak I, et al. Generation of active protein phosphatase $2 \mathrm{~A}$ is coupled to holoenzyme assembly. PLoS Biol 2007; 5:e155.

5 Sablina AA, Hector M, Colpaert N, Hahn WC. Identification of PP2A complexes and pathways involved in cell transformation. Cancer Res 2010; 70:10474-10484.

6 Ogris E, Gibson DM, Pallas DC. Protein phosphatase 2A subunit assembly: the catalytic subunit carboxy terminus is important for binding cellular B subunit but not polyomavirus middle tumor antigen. Oncogene 1997; 15:911-917.

7 Bryant JC, Westphal RS, Wadzinski BE. Methylated C-terminal leucine residue of PP2A catalytic subunit is important for binding of regulatory Balpha subunit. Biochem J 1999; 339(Pt 2):241-246.

8 Tolstykh T, Lee J, Vafai S, Stock JB. Carboxyl methylation regulates phosphoprotein phosphatase $2 \mathrm{~A}$ by controlling the association of regulatory B subunits. EMBO J 2000; 19:56825691.

9 Wei H, Ashby DG, Moreno CS, et al. Carboxymethylation of the PP2A catalytic subunit in Saccharomyces cerevisiae is required for efficient interaction with the B-type subunits Cdc55p and Rts1p. J Biol Chem 2001; 276:1570-1577.

10 Xing Y, Xu Y, Chen Y, et al. Structure of protein phosphatase 2A core enzyme bound to tumor-inducing toxins. Cell 2006; 127:341-353.

11 Rempola B, Kaniak A, Migdalski A, et al. Functional analysis of RRD1 (YIL153w) and RRD2 (YPL152w), which encode two putative activators of the phosphotyrosyl phosphatase activity of PP2A in Saccharomyces cerevisiae. Mol Gen Genet 2000; 262:1081-1092.

12 Jiang L, Stanevich V, Satyshur KA, et al. Structural basis of protein phosphatase 2A stable latency. Nat Commun 2013; 4:1699.

13 Fellner T, Lackner DH, Hombauer H, et al. A novel and essential mechanism determining specificity and activity of protein phosphatase 2A (PP2A) in vivo. Genes Dev 2003; 17:21382150.

14 Cayla X, Goris J, Hermann J, et al. Isolation and characterization of a tyrosyl phosphatase activator from rabbit skeletal muscle and Xenopus laevis oocytes. Biochemistry 1990; 29:658-667. 
15 Magnusdottir A, Stenmark P, Flodin S, et al. The crystal structure of a human PP2A phosphatase activator reveals a novel fold and highly conserved cleft implicated in protein-protein interactions. J Biol Chem 2006; 281:22434-22438.

16 Leulliot N, Vicentini G, Jordens J, et al. Crystal structure of the PP2A phosphatase activator: implications for its PP2Aspecific PPIase activity. Mol Cell 2006; 23:413-424.

17 Chao Y, Xing Y, Chen Y, et al. Structure and mechanism of the phosphotyrosyl phosphatase activator. Mol Cell 2006; 23:535546.

18 Ruediger R, Hentz M, Fait J, Mumby M, Walter G. Molecular model of the A subunit of protein phosphatase 2A: interaction with other subunits and tumor antigens. J Virol 1994; 68:123-129.

19 Xing Y, Li Z, Chen Y, et al. Structural mechanism of demethylation and inactivation of protein phosphatase 2A. Cell 2008; 133:154-163.

20 Wagner FW. Preparation of metal-free enzymes. Methods Enzymol 1988; 158:21-32.

21 Van Hoof C, Cayla X, Bosch M, Merlevede W, Goris J. The phosphotyrosyl phosphatase activator of protein phosphatase 2A. a novel purification method, immunological and enzymic characterization. Eur J Biochem 1994; 226:899-907.

22 Glusker JP, Katz AK, Bock CW. Metal ions in biological systems. Rigaku J 1999; 16:8-15.

23 Hsiao KJ, Sandberg AR, Li HC. The role of ATP and divalent cations in the regulation of a cardiac phosphorylase phosphatase (phosphoprotein phosphatase) of $\mathrm{Mr}=35,000 . \mathrm{J}$ Biol Chem 1978; 253:6901-6907.

24 Cai L, Chu Y, Wilson SE, Schlender KK. A metal-dependent form of protein phosphatase 2A. Biochem Biophys Res Commun 1995; 208:274-279.

25 Nishito Y, Usui H, Shinzawa-Itoh K, et al. Direct metal analyses of $\mathrm{Mn} 2+$-dependent and -independent protein phosphatase 2A from human erythrocytes detect zinc and iron only in the Mn2+independent one. FEBS Lett 1999; 447:29-33.

26 Finney LA, O'Halloran TV. Transition metal speciation in the cell: insights from the chemistry of metal ion receptors. Science 2003; 300:931-936.

27 Krezel A, Maret W. Zinc-buffering capacity of a eukaryotic cell at physiological pZn. J Biol Inorg Chem 2006; 11:1049-1062.

28 Petrat F, de Groot H, Rauen U. Subcellular distribution of chelatable iron: a laser scanning microscopic study in isolated hepatocytes and liver endothelial cells. Biochem J 2001; 356(Pt 1):61-69.

29 Outten CE, O'Halloran TV. Femtomolar sensitivity of metalloregulatory proteins controlling zinc homeostasis. Science 2001; 292:2488-2492.

30 Kay AR. Detecting and minimizing zinc contamination in physiological solutions. BMC Physiol 2004; 4:4.

31 Riordan JF, Vallee BL. Preparation of metal-free water. Methods Enzymol 1988; 158:3-6.

32 Holmquist B. Elimination of adventitious metals. Methods Enzymol 1988; 158:6-12.

33 Hartl FU, Bracher A, Hayer-Hartl M. Molecular chaperones in protein folding and proteostasis. Nature 2011; 475:324-332.
34 Preissler S, Deuerling E. Ribosome-associated chaperones as key players in proteostasis. Trends Biochem Sci 2012; 37:274283.

35 Pratt WB, Toft DO. Regulation of signaling protein function and trafficking by the hsp90/hsp70-based chaperone machinery. Exp Biol Med (Maywood) 2003; 228:111-133.

36 Alessi DR, Street AJ, Cohen P, Cohen PT. Inhibitor-2 functions like a chaperone to fold three expressed isoforms of mammalian protein phosphatase-1 into a conformation with the specificity and regulatory properties of the native enzyme. Eur J Biochem 1993; 213:1055-1066.

37 Turowski P, Fernandez A, Favre B, Lamb NJ, Hemmings BA. Differential methylation and altered conformation of cytoplasmic and nuclear forms of protein phosphatase 2A during cell cycle progression. J Cell Biol 1995; 129:397-410.

38 Lee JA, Pallas DC. Leucine carboxyl methyltransferase-1 is necessary for normal progression through mitosis in mammalian cells. J Biol Chem 2007; 282:30974-30984.

39 Longin S, Zwaenepoel K, Louis JV, et al. Selection of protein phosphatase $2 \mathrm{~A}$ regulatory subunits is mediated by the $\mathrm{C}$ terminus of the catalytic subunit. J Biol Chem 2007; 282:2697126980.

40 Silverstein AM, Barrow CA, Davis AJ, Mumby MC. Actions of PP2A on the MAP kinase pathway and apoptosis are mediated by distinct regulatory subunits. Proc Natl Acad Sci USA 2002; 99:4221-4226.

41 Li X, Scuderi A, Letsou A, Virshup DM. B56-associated protein phosphatase $2 \mathrm{~A}$ is required for survival and protects from apoptosis in Drosophila melanogaster. Mol Cell Biol 2002; 22:3674-3684.

42 Strack S, Cribbs JT, Gomez L. Critical role for protein phosphatase $2 \mathrm{~A}$ heterotrimers in mammalian cell survival. $J$ Biol Chem 2004; 279:47732-47739.

43 Otwinowski Z, Minor, W. Processing of X-ray diffraction data collected in oscillation mode. Methods Enzymol 1997; 276:307-326.

44 Emsley P, Cowtan K. Coot: model-building tools for molecular graphics. Acta Crystallogr D Biol Crystallogr 2004; 60(Pt 12 Pt 1):2126-2132.

45 Winn MD, Murshudov GN, Papiz MZ. Macromolecular TLS refinement in REFMAC at moderate resolutions. Methods Enzymol 2003; 374:300-321.

46 Tran HT, Ferrar TS, Ulke-Lemee A, Moorhead GB. Purification of PP2Ac from bovine heart. Methods Mol Biol 2007; 365:127-132.

(Supplementary information is linked to the online version of the paper on the Cell Research website.)

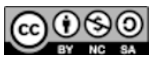

This work is licensed under the Creative Commons Attribution-NonCommercial-ShareAlike 3.0 Unported License. To view a copy of this license, visit http://creativecommons.org/licenses/by-nc-sa/3.0 